\title{
Las revisitas de indios: configuraciones de poder, silenciamientos y etnicidades en documentos coloniales tardíos (S. XVIII)
}

\author{
Alfredo Gómez Alcorta ${ }^{1}$ \\ Germán Morong Reyes ${ }^{2}$ \\ Francisco Ocaranza Bosio ${ }^{3}$
}

Recibido: 20 de junio de 2015 - Aprobado: 12 de agosto de 2015

\begin{abstract}
Resumen
Este trabajo explora el significado y alcance de las revisitas realizadas en los Andes durante el periodo de las reformas borbónicas (S. XVIII), centrándose en los Andes Meridionales (Tarata y Tarapacá). Presentamos algunos fragmentos de revisitas y sus particularidades, la naturaleza de su contenido y las coyunturas que las impulsaron. Se enfatiza el lazo existente entre las visitas y revisitas con los fenómenos de condicionamiento y modelación de la sociedad indígena. En tal sentido, exploramos el significado e importancia que les otorgara el Estado Colonial a visitas y revisitas -para la fijación de las tasas y retasas - y también el rol particular de estas últimas como dispositivos normativo-textuales en la construcción de una sociedad colonial normada. Nuestra propuesta consiste en sugerir que las revisitas constituyen una fuente ineludible para aproximarnos a la comprensión de un aspecto sustancial de la tensión social del último siglo de dominio colonial, como también en instrumentos textuales cuyos enunciados performan una realidad étnica a partir de los intereses de la fiscalidad imperial hispana.
\end{abstract}

Palabras clave: Etnohistoria, Historia colonial, Fiscalidad hispana, Revisitas, Ayllos, Documentos burocráticos.

Chileno. Académico, Escuela de Historia y Geografía, Facultad de Educación. Universidad Bernardo O'Higgins. Programa de Doctorado en Estudios Andinos PUCP. E-mail: Alfredo. gomezalcortar@gmail.com

2 Chileno. Académico, Escuela de Historia y Geografía, Facultad de Educación. Centro de Estudios Históricos, CEH. Universidad Bernardo O'Higgins. Doctorado en Estudios Americanos, Universidad de Santiago. E-mail: gmorongreyes@yahoo.es

3 Chileno. Académico, Director Escuela de Historia y Geografía, Facultad de Educación. Universidad Bernardo O'Higgins. E-mail: foranza@ubo.cl 


\title{
Revisiting indians: power configurations, silencing and ethnicities in delayed colonial documents (18th century)
}

\begin{abstract}
This paper explores the meaning and scope of the revisits conducted in the Andes during the period of the Bourbon reforms (18th Century), focusing on the Southern Andes (Tarata and Tarapaca). We present some fragments of revisits and their particularities, the nature of their contents and the joints that boosted them. It emphasizes the link between visits and revisits and the phenomena of conditioning and modeling the Indian society. In this regard, we explore the meaning and significance given by the Colonial State to visits and revisits, for fixing rates and rerates, and the particular role of the latter as normative textual devices in the building of a colonial society. We propose that revisits are a good way to approach the understanding of a substantial aspect of social tension in the last century of colonial domain, as well as the textual instruments whose statements inform an ethnic reality from the interests of the Spanish imperial taxation.
\end{abstract}

Keywords: ethnohistory, colonial history, Spanish taxation, revisits, Ayllos, bureaucratic documents.

\section{As revisitas de indios: configurações de poder, silenciamentos e etnias em documentos coloniais delongados (s. XVIII)}

\section{Resumo}

Este trabalho explora o significado e alcance das revisitas efetuadas nos Andes durante o período das reformas Bourbônicas (S. XVIII), com foco nos Andes Meridionais (Tarata e Tarapacá). Apresentamos alguns fragmentos de revisitas e suas particularidades, a natureza do seu conteúdo e as conjunturas que as impulsionaram. Enfatiza-se a ligação entre as visitas e revisitas com os fenômenos de condicionamento e modelagem da sociedade indígena. A este respeito, se explora o significado e importância que lhes outorga o Estado Colonial a visitas e revisitas -para a fixação de taxas e retaxas- e também o papel particular destas últimas como dispositivos normativo-textuais na construção de uma sociedade colonial regulada. Nossa proposta é propor que as revisitas constituam-se numa fonte iniludível para aproximarmos a compreensão de um aspecto substancial da tensão social no último século do domínio colonial, como também em instrumentos textuais cujas declarações constroem uma realidade étnica a partir dos interesses da tributação imperial espanhola.

Palavras-chave: Etno-história, história colonial, Tributação Hispana, Revisitas, Ayllos, Documentos burocráticos. 


\section{Problematización: Naturaleza y alcance metodológico de "Visitas" y "Revisitas"}

El presente estudio tiene como objetivo analizar fragmentos de algunos textos burocráticos coloniales tardíos, con el fin de determinar sus estrategias discursivas conducentes a modelar y performar una situación de etnicidad determinada en el espacio sur peruano del siglo XVIII. Para ello, hemos elegido fragmentos de dos documentos coloniales conocidos como revisitas indígenas, a saber: "La revisita de Codpa (Altos de Arica) de 177273" (Hidalgo, et.al., 2004) y "La revisita de Tarata de 1773-74" (Hidalgo, et.al., 1996), ambas realizadas por el Corregidor de Arica Demetrio Egan4. Aventuramos a sostener, preliminarmente, que estos documentos, más allá de su estatuto de fuentes para la reconstrucción etnohistórica de sociedades indígenas, permiten vislumbrar los dispositivos textuales de poder, las categorizaciones e imposiciones culturales, los silenciamientos estratégicos y las modelaciones arbitrarias que los funcionarios reales intentaron sobre las comunidades étnicas con fines tributarios. Ello nos sitúa en un nivel de exégesis distinto al de la historiografía legalista y la etnohistoria andina, en estricto rigor. Reconocemos, para este trabajo, nuestra cercanía al análisis de discurso en el sentido que éste, en las últimas décadas, ha considerado pertinente revisar las condiciones bajo las cuales se produce un documento escrito y sus reglas de enunciación en los siglos XVI-XVIII ${ }^{5}$. Se trata de un procedimiento metodológico aplicado sobre las fuentes históricas cuyo objeto no es ya la discusión sobre la veracidad del contenido, sino las condiciones y las maneras (históricas) en que ese contenido ha llegado a ser legítimo y aceptado. En este sentido, el interés por la revisita como fuente para la construcción de "realidades históricas" o, a lo menos, como soporte de validez en los resultados de investigaciones interdisciplinarias, ha dado paso a un interés cuyo objeto central es el texto mismo, en particular lo que se ha denominado su "discursividad".

Desde las investigaciones de Guevara Gil y Salomon (1994), este tipo de documentos (visitas y revisitas) han sido metodológicamente redefinidos, cambiando la mirada epistemológica con que se les había analizado. Como se ha sostenido, a lo menos desde la década de los 80 (Zagalsk, 2009: 14), este replanteo epistemológico recupera el sentido y las necesidades políticas imbricados en las visitas y revisitas de indios, tornándose fundamental el análisis de las fuentes, más que aportar datos sobre "etnicidades" y estruc-

4 Documentos largamente trabajados por Jorge Hidalgo (1996, 2004) en un proyecto de reconstrucción etnohistórica para la zona aludida.

5 Cfr. S. Gruzinski, 1995; W. Mignolo, 1981, 1992; B. Pastor, 1983; T. Todorov, 1982; M. López-Baralt, 1993; Barthes, 1970; M. Bajtín, 1982; T. Van Dijk; 1999. 
turas socioeconómicas y culturales consolidadas, tiende a registrar proyectos coloniales estructurantes (Zagalski, 2009: 20). Por ello, se habla de las visitas como "dramatizaciones o teatralizaciones en tanto que la visita y revisita constituye un proceso de reconocimiento de otro social -los indios- y, al mismo tiempo, un evento ritualizado que busca adecuar la sociedad y las conductas a modelos impulsados por la corona y la iglesia" (Guevara Gil y Salomón, 1994: 6; Zagalski, 2009: 20), contienen más información sobre los cambios acaecidos en el marco del dominio colonial que sobre una supuesta andinidad, inmemorial e inmutable ${ }^{6}$.

Anterior a la emergencia y cuestionamiento que la teoría de los discursos y la historiografía crítica ha efectuado sobre los documentos coloniales (históricos, burocráticos) en tanto reproductores de datos para una situación etnográfica determinada, dos han sido los paradigmas constitutivos que han configurado a estas fuentes como objetos de análisis histórico y etnohistórico (Guevara Gil y Salomon, 1994: 6-8).

El primero, inspirado en la tradición de la historiografía legal, había estudiado las modalidades del ejercicio de la institucionalidad hispana en el control y reglamentación imperial de los territorios colonizados, desde una perspectiva más descriptiva que interpretativa. En este enfoque, los nombres y acciones de los visitados son minimizados $u$ omitidos, siendo las instituciones, las normas y las leyes indianas los objetos de indagación ${ }^{7}$. El segundo paradigma, denominado etnohistórico, del cual fuera impulsor John Murra, cambió estas prioridades para establecer, en los papeles burocráticos (en particular las visitas), la voz indígena y una suerte de reconstrucción diacrónica de los grupos étnicos andinos; grupos e individuos que "hablaban" de sí en los documentos escritos (Murra, 1964; 1968). Recordemos que la etnohistoria, en tanto "campo de saber", se inició en función de rescatar la etnicidad que asomaba en los papeles institucionales que constituían al indígena como objeto de legalidad .

Tradicionalmente, y siguiendo el segundo paradigma, visitas y revisitas se han estudiado desde un análisis heurístico "clásico", utilizándolas como

6 Más aún, crónicas, relaciones, visitas y revisitas en el razonar disciplinario de algunos etnohistoriadores, constituyeron las fuentes predilectas para "descubrir" al otro indígena en la lógica de una antropología histórica que busca datos confirmatorios en la constitución de continuidades culturales (Cfr. Zseminski, 1983; Bouysse-Cassagne, 1987; Harris, 1987)

7 Las investigaciones de Guillermo Céspedes del Castillo (1946) y José María Ots Capdequí (1969) son claros exponentes de esta posición.

8 Cabe aquí mencionar toda una tradición etnohistórica iniciada por Luis E. Valcárcel y continuada por John Murra, Tom Zuidema, María Rostworowski, Franklin Pease, Waldemar Espinoza, entre otros. Para México son relevantes los nombres de Edmundo O'Gorman y Miguel León Portilla. 
fuentes de información respecto del marco demográfico sur peruano ${ }^{9}$ y norte chileno (correspondiente a la zona de Tarata y Tarapacá), además de ser fuentes de antecedentes para las conflictividades relativas a los problemas de sucesión cacical y el estado de las relaciones interétnicas (Hidalgo, 1997: 425-442). En términos retrospectivos, las revisitas a las poblaciones indígenas fueron consideradas como fuentes documentales que proporcionaban información de primera mano sobre los rasgos sociodemográficos y étnicos de los Andes meridionales (Hidalgo, 1988; Wachtel, 1978; Pease, 1978; Gómez, 2008; Gómez et al., 2009; Gómez et al., 2010). Sus antecedentes documentales han sido utilizados para plantear la continuidad en el modelo organizacional económico y social del ayllo prehispánico, asignándole a sus relaciones de integración económica extrarregional el valor de continuidades históricas, inspiradas en la perspectiva murriana de la verticalidad andina (Hidalgo, 1996: 20).

En nuestra perspectiva analítica estos instrumentos, así como los actos que les dieron origen, terminaban por "normalizar" de forma definitiva a las comunidades andinas. Su formato preestablecido y reproducido sistemáticamente durante los siglos coloniales no hacía más que reafirmar el modelo toledano de reducciones y controles tributarios (Levillier, 1940: 64). Bajo esta línea de argumentación, estos documentos entrañan antecedentes que nos remiten a las circunstancias en que opera la sociedad predominante y su relación con la sociedad indígena, subsistente durante los siglos de colonialismo al usufructo y la expoliación (Golte, 1980: 34). En este sentido, la narración que contiene presenta lugares, dispositivos y procedimientos que responden a esquemas burocráticos y jerarquías políticas que se cumplen con gran formalidad. Ellos aluden a una "realidad" y presentan un programa discursivo de naturaleza política con los objetivos coloniales.

\section{La estructura de las revisitas como colonialidad del saber burocrático}

Las visitas o padrones de población fueron instrumentos de cómputos precedidos y seguidos de un largo trabajo legal y burocrático de múltiples implicancias, tanto administrativas como económicas, que materialmente se expresaban en gravámenes sobre la población. Estos últimos lesionaban tanto la economía colectiva de las comunidades andinas y, al mismo tiempo, deterioraban la condición individual de los indígenas tributarios. En este sentido,

9 Problemática que había sido abordada superficialmente en el transcurso del proyecto Fondecyt No 1941199 - 1995. Investigador responsable: Dr. Jorge Hidalgo L. "Historia de los Pueblos Andinos de Arica, Tarapacá y Atacama en el contexto colonial hispano". Universidad de Tarapacá. 
el registro de la población determinaba la imposición transversal de las cargas impositivas a las comunidades andinas, por lo que las consecuencias de la realización de las visitas y las consecuentes revisitas no eran hechos fortuitos y tangenciales sino planificados, desatando consecuencias determinantes para la vida económica de los indígenas y demás castas y clases subalternizadas.

La función y naturaleza de estos documentos varió sustancialmente durante los siglos coloniales. En la segunda mitad del siglo XVI se concibieron como latas recopilaciones de información general sobre las etnias reducidas, los que con el paso del tiempo se transformaron en documentos con una matriz común que sólo se replicaba cada vez que se despachaba la orden de reenumeración de la población para su retasación. Sin embargo, las distinciones se encuentran tanto en la naturaleza de su información como en los efectos que van generando a través del tiempo. Sería un error pensar que su aplicación no tenía mayores impactos en la población y que sus instrucciones y consecuencias se recibían pasivamente por la población originaria. Creemos que su realización, como los efectos que precipitaban, gatillaban cambios significativos para las comunidades, y de modo particular, presionaban a las autoridades étnicas ${ }^{10}$.

La uniformidad de los documentos nos sugiere un esfuerzo de permanente modelación del indigenado en tanto proyecto colonial estructurante. Esta afirmación pone en evidencia la relación de "colonialidad" como un "proceso" que cuaja en el período tardo colonial, es decir, en el plano del modelo de sociedad que se deseaba imponer uniformemente en el contexto andino.

La estructura de estos documentos coloniales, de modo general, es la siguiente: los autos de ordenanzas que mandan su realización, obedecimientos, los consecuentes nombramientos de los realizadores, las instrucciones para su realización, el recuento de la población según las categorías censales detallando edades, nombres y número de integrantes de las unidades

10 En muchas ocasiones, el cacique debía transformarse en un verdadero cobrador, oprimiendo a su propia población como un modo de solventar los altos costos del pago del tributo cuando se incrementaban los fugados o no se podían certificar mediante debido proceso las muertes de tributarios. De modo sistemático se transgredía abiertamente las Leyes de Indias en tanto no atendían a la Ley XV del libro V, que versaba "Que los indios no sean agraviados en tributar por muertos y ausentes. Somos informado, [sic] que al tiempo de cobrar los tributos de los indios les hacen pagar por entero, conforme á la última visita, sin atención á que de estos los muertos son algunos tributarios, y otros se han huido, y como los pagan los Caciques, cobrar lo que pagaron de las mujeres, hermanos, hijos y parientes de los muertos, o huidos. Mandamos, que Virreyes, Audiencias, y Gobernadores, provean el remedio, de forma, que en esta parte no reciban agravio los indios, ni Caciques. Don Felipe III en San Lorenzo al 6 de junio de 1609". (Recopilación de las Leyes de Indias. Libro Quinto, de los Tributos y Tasas de los Indios). 
tributarias o familias ${ }^{11}$ o tributarios solteros, ${ }^{12}$ más una conclusión que da cuenta, sumariamente, de los resultados numéricos del recuento. Pueden incluir anexos relativos a los cambios sufridos por la población en el período intercensal como fallecimientos o las sucesiones que ha sufrido el cargo de cacique. Los decretos e instrucciones de las revisitas son del tenor que sigue:

"Que se abra la Numeracion con el Principal del Ayllo, y su muger si la tubiere, y sus hijos a cada uno con sus edades; sacando al un margen la de los Barones, y al otro la de las embras prociguiendo en la misma orden con los demas casados del Ayllo hasta que se acabe; y luego distintamente se podran los Viudos con sus Hijos e Hijas, los Solteros, los Reserbados de Tributos por tener cinquenta años de edad, o por otras enfermedades que los imposibiliten de trabaxar, o finalmente por Provisiones particulares del Superior Govierno todos con sus Mugeres e Hijos, y sus edades en la forma dicha=14" Que despues de practicado todo lo expresado, se ponga la numeracion de las Mugeres Viudas, y solteras con sus Hijos e hijas, y al fin de todos los Huerfanos Menores de Diez y ocho años que no tengan padres vivos con adbertencia [sic] de que el que estuviese casado sin haber cumplido la edad referida, es tributario, y se ha de poner con los demas en su lugar $=15^{\prime \prime}$ Que al fin de la Revicita hecha en cada repartimiento, se ponga memoria de los Yndios muertos, y ausentes con expecificacion del tiempo, o parte donde murieron los unos, y la Causa de la dicha ausencia de los otros autorisada esta con la firma de sus respectibos Curas; y si se hallaren más Yndios de los contenidos en el Padron, y libros de baptismos se pondran por nuebamente manifestados en su lugar = 16 " Que respecto de que en la clase de ausentes hai divercidad; porque de unos se save el lugar donde residen, y las Justicias de el son obligados a darles a los Casiquez, y Cobradores todo el aucilio para cobrarles sus Tributos, y que tengan entendido que la fuga no les ha de servir de alivio, y de los otros se ignora absolutamnete su paradero: separadamente se numeren con esta distincion, y de tal suerte que no

11 Estas disposiciones se establecen en la Ley XXIII de las Recopilaciones de Indias que versa: "Que en padrones de las tassas se pongan los hijos, y sus edades. Por los padrones de tassas de los indios, en que mandamos se pongan también los hijos, se han de averiguar las edades, y obligaciones, que tuvieren de pagarlas, en que debe haver muy buen orden, para escusar pleitos, y no tener necesidad de valerse de los padrones que hazen los curas, porque no se persuadan en ninguna forma los indios a que estos se hazen en orden al interés de los españoles, sino para el fin que se introdujeron, como Ministros de la Iglesia. Felipe III en Madrid a 10 de octubre de 1618". (Recopilación de las Leyes de Indias. Libro Quinto, de los Tributos y Tasas de los Indios).

12 Ley VII. Que los indios solteros tributen desde diez y ocho años, si no estuviere introducido otro tiempo. (Recopilación de las Leyes de Indias. Libro Quinto, de los Tributos y Tasas de los Indios). 
se contrabenga a lo prebenido por la ley quarenta y quatro del titulo sinco libro seis de las recopiladas". ${ }^{13}$

En efecto, este documento también testimonia la hegemonía hispana, la derrota indígena y su consecuente sumisión al orden colonial; coarta el disenso mediante sus medidas cautelares y sanciones que impone, tanto a las propias autoridades responsables de llevar adelante el conteo de población como a la población originaria y sus autoridades. El texto de las revisitas no admite realidades descriptivas, impone panoramas planificados y recreados para su propia finalidad. ${ }^{14}$; admite muy pocos cambios estructurales en la población, con exigencias burocráticas dificilísimas y, en apariencia para muchos, casi inalcanzable por sus altas demandas impositivas (Díaz y Morong, 2006: 129-152). Su estructura rígida y ordenación prescriptiva de la realidad constituyen la naturaleza radical de este tipo de documentación. En efecto, creemos que los documentos de las visitas y revisitas andinas, en mayor medida los tardíos, guardan más relación con una sociedad férreamente normada, por lo que adherimos a la tesis de que estos documentos son más "creadores de sentido antes que reflejos o recipientes de una realidad" (Martínez, 2000: 14).

\section{Configuraciones de Poder: Formato y propósitos de la institución de la revisita en el S. XVIII}

Como se advirtió, indagaremos parcialmente en las revisitas coloniales tardías (siglo XVIII), tomando como ejemplo algunas correspondientes al sur peruano. Hacemos esta distinción ya que las visitas tempranas, desde la Visita General de Toledo hasta las realizadas, inclusive, en el siglo XVII, requieren de una mirada con énfasis metodológicos diferentes, cuestión que aquí no abordaremos ${ }^{15}$.

Las categorías censales de las visitas comenzaron a constituirse en el transcurso del siglo XVII, en realidades legales a las que las familias y los individuos, según sus particulares intereses, pugnaban por adscribirse 0 renunciar. Durante el siglo XVII y los inicios del siglo XVIII, las categorías

13 Archivo Nacional de Chile. Administrativo de Arica Leg. 4. Revisita de Tarata de D. Egan, 1773-74. F4R/F4V (Hidalgo et al. 1996, 22)

14 En atención a la Ley XXVII. "Que los visitadores vean, y reconozcan los pueblos, que van a tassar. Muchas vezes se hazen tassas de tributos, por informaciones, sin estar presentes los visitadores, ver, ni reconocer los pueblos, y su calidad, de que resultan inconvenientes. Mandamos que los visitadores vean los pueblos por sus mismas personas, y reconoscan el numero de los indios y su posibilidad, para que con mas justificación, y entera noticia procedan. El emperador D. Carlos en Monçon a 19 de diciembre de 1534". (Recopilación de las Leyes de Indias. Libro Sexto, Título V, de los Tributos y Tasas de los Indios).

15 Remitimos al lector al interesante trabajo de Paula Zagalski (ver bibliografía). La autora se ocupa aquí de las revisitas en el período post-toledano. 
censales representaban verdaderos criterios de clasificación socioétnica, tanto como de cuantificación poblacional. El gran salto de este sistema de conteos es desarrollado en la década de 1680 con la redefinición tributaria de la población en la que son incorporados forasteros, mestizos y yanaconas. El virrey duque de La Palata había realizado una ampliación radical de la población en la que recayó el cobro del canon fiscal. De este modo, las visitas comenzaron a ser instrumentos de conteo detallado de la población en que sus categorías étnicas-culturales se confundían con categorías fiscales, no sólo por la distinción de la posesión de tierras, el acceso a derechos, beneficios ancestrales y comunitarios, sino por una delimitación estricta respecto de la condición social y la relación fiscal que se establecía con el Estado colonial. Las renuncias de su estatus y la búsqueda de nuevas condiciones étnicas y económicas fueron un mecanismo para aminorar las tensiones de la relación con el fisco colonial, masificándose la figura del forastero a proporciones alarmantes para la autoridad.

En este esquema la existencia comunitaria se vincula al reconocimiento fiscal

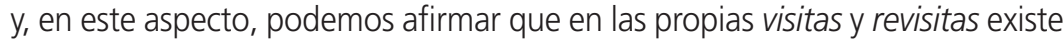
una preconcepción de las comunidades, una existencia previamente sancionada por las propias numeraciones. Estos son los "horizontes" fiscales y administrativos que las comunidades no pueden evadir. De este modo se establece:

"9 Que les manden y apremien a los Casiquez a que exhiban el Padron de la Revicita antesedente y la ultima Retaza por donde pagan sus tributos y caresiendo de estos Documentos manifiesten las Listas que tuvieren para la cobransa de tributos, para que puedan traerse a cotejo con los Libros de los Curas, y se benga a conocimiento de los que han muerto, y han nasido; de modo que no se oculten Yndios algunos sino que se numeren todos efectibamente so pena de que en caso de ser descubierto lo contrario, se les pribara de sus ofizios, y que seran castigados con rrigor" (Hidalgo et al. 2004).

La exclusión concluye en la sanción, mediante el castigo físico por azotes, trasquilación y, en última instancia, el envío a la prisión de Valdivia o a las minas de Potosí, que constituyen un viaje sin retorno. Se advierte:

" $16^{\circ}$ Que respecto de que en la clase de ausentes hay diversidad, porque de unos se saue el Lugar donde residen, y las Justicias de el son obligados a darles a los Casiquez, y Cobradores todo el aucilio para cobrarles sus tributos, y que tengan entendido que la fuga no les ha de servir de alivio, y de los otros se ignora absolutamente su paradero separadamente se numeren con esta distincion y de tal suerte que no se contrabengan a lo prebenido por la Ley quarenta y quatro del titulo sinco Libro seis de las recopiladas. (Hidalgo et al. 2004, f4v) 
Lo que observamos en el documento es la reiteración majadera de la "palabra autorizada" bajo la forma de disposición que "norma" y "delimita" la conducta individual y colectiva. El acto en sí es de intromisión abrupta y violenta en la vida cotidiana y política de la comunidad, con profundas implicancias económicas que comprometen la subsistencia de ella. Éstos representan actos de intromisión forzosa y averiguación incisiva que fracturan los acomodos y ajustes que han hecho posible la subsistencia material de las comunidades. Su costo es alto, conlleva a un nuevo proceso de ajustes de cuentas y de recursos, obligando a los curacas a reorganizar estratégicamente los pactos y acomodos con cada tributario de su comunidad, al amparo de ciertas prácticas rituales. Es un proceso complejo, una componenda costosa en la que se sustenta parte de la legitimidad del poder tradicional. Sus disposiciones hacen que cualquier enmienda o reclamo ameriten un proceso diferente al de los autos de revisita y de la numeración propiamente tales, remitiéndose primeramente a la autoridad del cacique para su elevación a las autoridades superiores. Al respecto, las instrucciones regulares establecen:

"18 Que si algun Yndio para no ser enumerado entre los tributarios alegare ser Mestiso ofreciendo dar Ynformacion despues de haberlo numerando en el Pueblo, o Ayllo donde se hallare, se le reciba con citacion del Casique su comun Defensor de la real Hacienda, e Ynteresados en las Mitas, sin excederse en Declararlo por libre respecto de ser esta facultad privatiba al Superior Govierno donde se deberan remitir las Diligencias, o entregarselas a la parte sin agregarla a los autos de revicita, no entendiendose esto con que estuvieren en posecion de tales Mestisos $19^{\circ}=$ Que si huviere algunos cholos cuyo misto se procrea de Mestiso e Yndio o viseversa, hauidos en Matrimonio, o fuera del se numeren tambien separadamente respecto de que estan sujetos a la paga de tributos aunque esentos de la Mita, y servicios perzonales, sin omitir expesificacion de sus Edades Mugerez e hijos". (Hidalgo et al., 2004, F. 5r y 5v).

No creemos que las categorías de familia o de unidad económica tributaria reproducidas en las revisitas correspondan a un correlato andino de sociedad. Parecen, más bien, categorías impuestas, ya que niegan la existencia de familias extendidas mediante la atomización familiar. ${ }^{16}$ Su objetivo es la concentración económica y esto oculta las bases de las relaciones reciprocitarias y de la propiedad comunal. Del mismo modo se organizan categorías étnicas y fiscales, imponiendo de modo ficticio distinciones, con el fin de incrementar las arcas reales. Consecuentemente a este panorama se establece:

16 Parece prudente atender a los procesos de construcción familiar del periodo moderno en Louis Henry, Manual de demografía histórica (Barcelona: Editorial Crítica, 1983). 
$" 20^{\circ}=$ Que igualmente se empadronen en el numero de tributarios, por serlo segun Ley recopilada, los que se titulan Sambaigos que son los que dimanan de Negro e Yndio o viceversa $21^{\circ}=$ Que si huviere mediado mucho tiempo desde la actuacion de la ultima Revicita y que no se encuentren en el devido orden los Libros de Baptismos para venir a conocimiento de los que despues de esta han nacido se manejasen por los Padrones de Confeciones de los Curas, y por los anuales que se huvieren hecho para la Cobransa de tributos $22^{\circ}=$ que se hayan de distinguir forzosamente las clases de los Yndios assi originarios como forasteros, para que puedan cargarseles, a cada vno su respectiba quota poniendo separacion los dichos Forasteros que gosan Tierras, por si o por sus Mugeres de aquellos que absolutamente no las tienen". (Hidalgo et al., 2004, F. 5 r y 5v).

Ciertamente, el discurso hispano colonial define etnicidades a la altura de las necesidades que impone el régimen colonial. Ello tiene claras repercusiones en el campo de la imposición de identidades étnicas (Bixio, 2005: 23; Morong, 2011: 174-75) en el sentido de que se construye una clara clasificación estamental, directamente vinculada a los roles económicos que construyó el periodo colonial; indios, yanaconas, negros, mulatos, zambaigos, indios de mita, indios forasteros, etc. Esta clasificación identitaria era necesaria al control y fiscalización imperial.

Por otra parte, la problemática económica y social que significó para las comunidades andinas el denominado reparto forzoso de mercancías en el siglo XVIII (Golte, 1980; O'Phelan, 1988, 1995, 1997; Gómez, 2008), nos puede dar alguna idea de cómo la autonomía del cacique en la esfera de la producción de información o de certificación de información, debió estar determinada por las propias necesidades individuales y comunitarias. Esta autonomía la observamos en las instrucciones, cuando se establece que:

" $23^{\circ}=$ Que se obserbe el metodo expresado en la numeracion de cada repartimiento de los que componen la Provincia, y assi concluida se provea vn auto mandando a los Casiquez que justifiquen con recaudos autenticos los que huvieren dado por muertos y ausentes, reciviendoles Ynformacion de testigos con citacion del Defensor de Real Hazienda; para la qual se les señalara vn termino competente que no hasiendolo dentro del se pondra por tributario como los demas, cuyas diligencias se practicaran con todas las que se concideren conducentes a que no haya fraude alguno en la materia= 24 Que precedidas las dichas actuaciones se provea otro Auto dandoles traslado de dicha Revicita; para que si tuviesen que pedir contra ella, lo hagan en el termino que se les señalare, en la inteligencia que pasado este prescrivira qualquiera accion, y se embiaran los Autos al Superior Govierno, para que resuelva lo que 26 Que se averiguen los Bienes o rentas de Comunidad que tienen los Yndios de cada repartimiento expecificandose con toda 
claridad, y distincion a cuyo fin los manifestaran los Curas, y Casiquez y esta razon se pondra al pie de la revicita de el que concluida en el todo de la Provincia se despacharan sus autos originales al Superior Govierno, acompanados del respectibo Ynforme Jurado dejandose testimonio autorisado de la revicita de cada repartimiento con su correspondiente Caxa de Comunidad, y de no haberla en el Archibo de la Provincia para el Govierno de los Correxidores que la sirvieren interin no se efectua nueba rumeracion". (Hidalgo et al., 2004, f. 5r y 5v).

Estas tensiones, presiones sociales y cambios en el rol tradicional de la autoridad étnica se han abordado por Tord $(1974,1981)$, Golte $(1976,1980)$, Moreno (1977), Nicolás Sánchez-Albornoz (1978) y O'Phelan (1988), entre otros. Enfatizando algunos sus efectos económicos y otros sus consecuencias sociodemográficas para la población. Por esto, es difícil asumir que estos documentos están refrendados por la buena voluntad y el afán de policía y servicio al rey por parte de los funcionarios coloniales. Admitimos la posibilidad de su burda manipulación en función a los intereses del corregidor en colusión con el propio cacique como una práctica cotidiana.

Esta "expectativa" colonial y, a la vez, imposición modeladora de una realidad sociodemográfica y política "aparente" de las comunidades, es la fuente de la mayor parte de sus conflictos. De ella derivan parte significativa de las tramitaciones que los indígenas deben iniciar ante el "Superior Gobierno"; para certificar edades, condiciones tributarias de exentos, fallecimientos, liberaciones del pago al cacique y, sobre todo, las presiones que la propia autoridad étnica realiza sobre la población originaria y los recursos comunales para compensar el pago de tributo por las migraciones o huidas de la población. La comunidad debe, en efecto, luchar sistemáticamente con un esquema de población impuesto, extremadamente férreo y determinante, que niega el dinamismo y la organicidad propia de las comunidades indígenas. En otras palabras, el patrón normaliza tanto la producción tributaria como la organización socio-demográfica de las poblaciones andinas.

\section{Silenciamientos y reconfiguraciones étnicas; contexto y posibilidades de lectura de estos documentos coloniales}

Las revisitas analizadas, en efecto, traslucen una realidad de dimensión humana fundamentalmente relativa a la dimensión biológica, por lo que nuestra hipótesis apunta a que sus antecedentes generales presentan importantes distorsiones de la realidad biológica etaria y reproductiva de las sociedades andinas de Tarapacá y Tarata. Estas disonancias implican un distanciamiento de las voces étnicas tan anheladas por los estudios etnohistóricos. Sus categorías preestablecidas pueden estar ocultando las verdaderas dimensiones sociodemográficas de los indígenas de Tarata y los "Altos de Arica" a fines 
del siglo XVIII. De hecho, y sólo como ejemplo, ellas aplican una taxonomía étnica para mestizos mulatos y zambaigos que, en muchos casos, puede resultar ficticia frente a su somera apreciación por el tinte de la piel. A pesar de las eruditas apreciaciones de época, tales asignaciones de etnicidad exigían de documentos fidedignos para ser desvirtuadas, por lo que es posible que se hayan prestado para serias distorsiones y abusos. Lo mismo para la atribución antojadiza de las edades a las personas, con el claro propósito de abultar las categorías de tributarios. Recordemos que, para una población de alta movilidad producto de los fenómenos demográficos del siglo XVIII, contar con certificaciones parroquiales para dar cuenta fidedignamente de las edades, así como las defunciones, podía ser un trámite excesivamente engorroso, fundamentalmente para la categoría de los forasteros. El regreso de cada quien a su comunidad de origen para obtener un documento certificatorio también les imponía un encuentro con la autoridad religiosa de la doctrina, lo que podía involucrarlos en nuevos conflictos como el cobro de saldos de pago de impuestos o delaciones a la autoridad étnica por deuda.

Podremos postular la coexistencia entre el formato de la realidad -narrativizada en el documento- y la propia historicidad de la sociedad indígena en Tarata y Tarapacá (Gómez, 2009; 2012). Ambas dimensiones no son homólogas; coexisten y representan escenarios de realidad paralelos en que una dimensión escritural burocrática encubre e invisibiliza lo que podemos imaginar como una "realidad étnica" determinada. Así también, en su intento de sacudirse de las pesadas cargas fiscales, los indios recurren a la mentira, la simulación, la evasión, la ambigüedad, etc. Todo ello, configura un cuadro documental preñado de artificios, distorsiones y modelamientos preestablecidos que cumplen la función de un teatro discursivo orientado al control y la exacción tributaria. En realidad, estamos en presencia de un acto de autoridad colonial que se despliega en los más lejanos y apartados pueblos del sur peruano.

El corregidor con su comitiva se hacía presente portando instrumentos de descripción que, de cierta manera, construyeron una realidad: hacían del campesino andino un indio, un cholo, un zambaigo, señalando y controlando el destino de los jóvenes, aprobando autoridades, investigando y haciendo observaciones en terreno sobre los cargos, la cantidad de tierras de reparto y otras. La información de las revisitas y sus irregularidades, particularmente aquellas que dicen relación a la falta de correlato con los procesos naturales de una población biológica (tasa de fallecimientos por edades, por ejemplo), así como irregularidades en las categorías etarias (en casi todas las edades económicamente productivas son elevadas), muestran un propósito performador al "representar" a las comunidades como entidades que se sostienen en el tiempo con escasos cambios en sus estructuras. Nuestro siguiente paso es comentar algunas cifras, obtenidas de la tabulación de la información contenida en las revisitas analizadas. El análisis seguirá la ordenación del material graficado. 
Gráfico 1: Situación de Masculinidad en los Altos de Arica, 1750

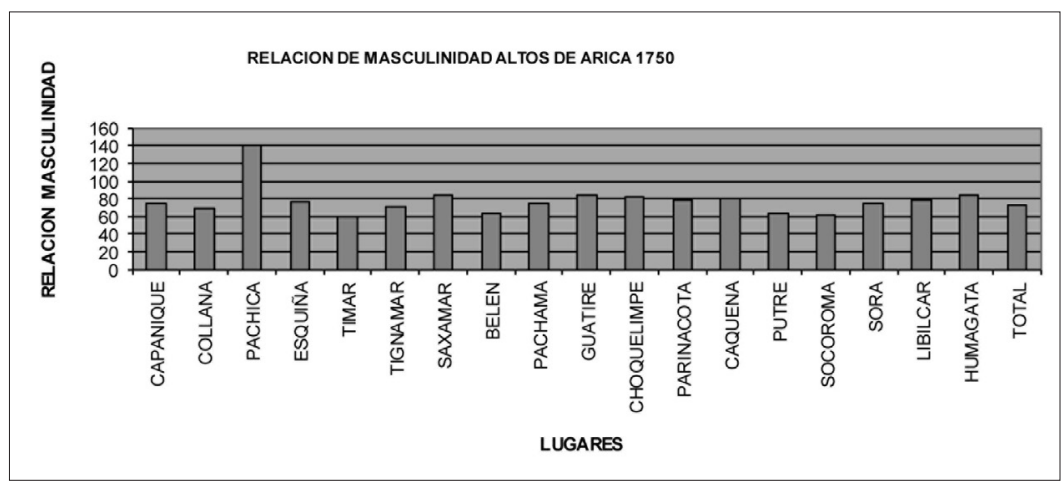

Fuente: Registro efectuado según las cifras proporcionadas por Jorge Hidalgo, Revisita a los Altos de Arica en 1750. Ed. Universidad del Norte, 1978. Gráfico de elaboración propia.

Esta información nos muestra un panorama complejo para las poblaciones andinas aquí representadas. En efecto, el índice de masculinidad es para casi todas las parcialidades muy bajo, debido a las presiones fiscales y a la imposición de la mita (Tord, 1974; Golte, 1980, entre otros). En este periodo (1750-60) deben expresarse signos de recuperación demográfica, sin embargo, las cifras muestran un gran déficit de varones en las comunidades. Sólo un ayllo, el de Pachica, tuvo un índice muy superior al regular, motivado quizás por condiciones materiales particulares o una concentración por razones productivas que ayudaría a compensar el índice en otros ayllos. Aun así los rangos inferiores de este índice (entre 60 y 80 ) son muy bajos y pudieron haber comprometido a las comunidades bajo el esquema monográfico que se difundía en las doctrinas.

Gráfico 2: Relación Masculinidad en los Ayllus de Tarata 1773-1774.

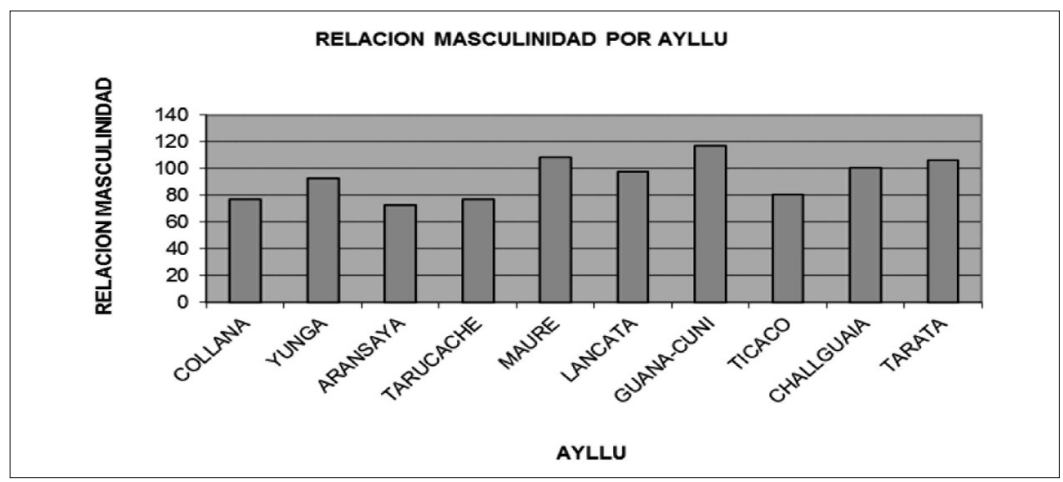

Fuente: Registro efectuado según las cifras proporcionadas por Jorge Hidalgo, Revisita a los Altos de Arica en 1750. Ed. Universidad del Norte, 1978. Gráfico de elaboración propia. 
En este esquema observamos antecedentes que podemos atribuir a cierta recuperación del índice de masculinidad y, en consecuencia, de la población en general, si deseamos creer que el panorama anterior era común a las comunidades andinas producto de la presión y los compromisos fiscales (Hidalgo, 1996). Veinte años después este índice llega a un 20,9\% de la comunidad de Tarata. Sin embargo, hay cifras por debajo de 80 que se asemejan al panorama anterior. Estas diferencias pueden deberse a la distribución temporal de la mita, sin embargo, las revisitas no dan cuenta de movilizadas periódicas, sino de registros cerrados que hacen inadmisible la ausencia de un contingente considerable en el conteo. ¿Por qué diferencias tan sustanciales en uno y otro ayllo? Puede ser que las cifras proporcionadas se hayan modificado para ajustar los registros a un número regular esperable.

Grafico 3: Defunciones según rango etario en los Ayllus de Tarata 1765.

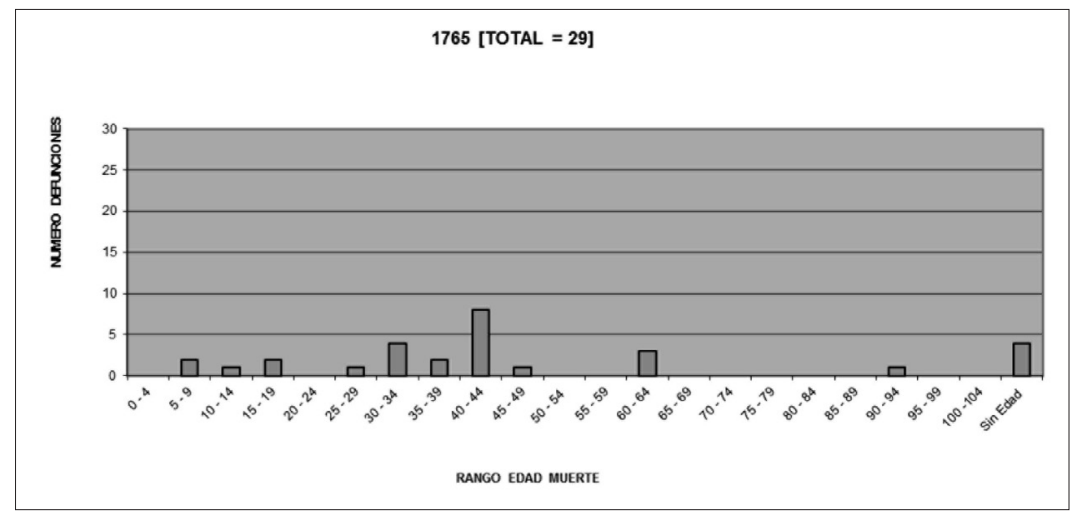

Fuente: Registro efectuado según las cifras proporcionadas por Jorge Hidalgo, Revisita a los Altos de Arica en 1750. Ed. Universidad del Norte, 1978. Gráfico de elaboración propia.

Un primer problema es la ausencia, durante un año, en un corregimiento donde habitan más de 3.000 personas, de fallecimientos de niños bajo la edad de los 4 años. Es esperable que el mayor número de fallecimientos se registren en este periodo, fundamentalmente entre los 2 y 4 años, durante el destete, por el cambio de la dieta. Es posible que las familias no informen de tales fallecimientos, aun cuando faltarían a la obligación de informar del nacimiento al cura párroco. Llama la atención la concentración de defunciones en el rango etario de los 40-44 años. Es posible que este registro sea aleatorio, pero coincide con la esperanza de vida de estas comunidades de acuerdo a las condiciones de vida. ${ }^{17}$

17 Para estos efectos remítase a Hollingsworth, T.H, Demografía Histórica (México: Fondo de Cultura Económica, 1983), y Spiegelman, Montimer, Introducción a la demografía (México: Fondo de Cultura Económica, 1985). 
Otro aspecto relevante es la existencia de fallecimientos sin registro de edad. Parece poco verosímil que en una comunidad que está siendo pesquisada sistemáticamente por el cura doctrinero -para el pago de los servicios del sacramento del bautismo- no existan datos concretos, siendo esta materia propia de la administración parroquial. Si los fallecimientos correspondieran a un número significativo de neonatos, ellos no quedaban exentos del registro, dado que era política religiosa el "aconsejar a la mujer embarazada intra confessionem, que en caso de aborto, cuide que no se prive al feto de la gracia del bautismo" ${ }^{18}$. Cabe aquí mencionar que, dentro de las obligaciones parroquiales, se encontraba la fabricación de matrículas que tenían la función de realizar descripciones generales de los feligreses de la doctrina. Ella correspondía a la organización y clasificación de la "condición religiosa de la población". No sólo se enumeraba en las matrículas a las personas adultas por una cuestión numérica, sino para obligarles al precepto de la confesión y la comunión, incluyendo a las mujeres y a los niños de todas las edades, haciendo distingo especial de quienes tenían la obligación de confesar y comulgar en el año. Toda la población se ordenaba no sólo por categorías familiares y sus componentes, sino por lugar de residencia, distinguiendo con una $C$ y una $C r$ entre quienes fueron admitidos a la comunión y quienes han recibido el crisma o confirmación. Estos son los "libros de confesiones" a los que las ordenanzas de revisita apuntaban; fueron registros pormenorizados de la población. Por ello eran fundamentales a la hora de iniciar la revisita, ya que se iba certificando la identidad de los convocados a la numeración. Es por estas razones que los propios registros muestren falencias en cuanto a la identidad y condición de los fallecidos.

Gráfico 4: Situación de Mortalidad en los Ayllus de Tarata en 1768

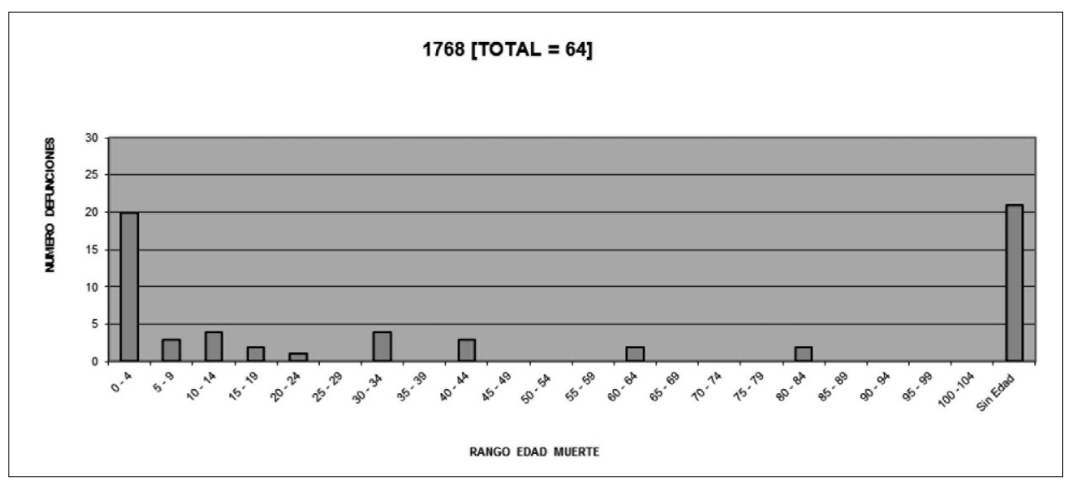

Fuente: Registro efectuado según las cifras proporcionadas por Jorge Hidalgo, Revisita a los Altos de Arica en 1750. Ed. Universidad del Norte, 1978. Gráfico de elaboración propia.

18 Justo Donoso, Manual del párroco americano (Santiago: Imprenta Progreso, 1844). 
Aquí vemos la confirmación de lo que comentamos en el análisis del gráfico anterior. De acuerdo a las condiciones biológicas y culturales de la población es esperable un número considerable de fallecimientos en el rango etario más temprano. Luego, nos llama la atención el elevado número de fallecidos sin edad, es decir, sin identificación ni estimación de su edad por aproximación. Representan un 33,8\%, lo que es un porcentaje muy alto. ¿Es posible que más de un tercio de los fallecidos en un año no tuvieran ninguna referencia etaria? Esto es inverosímil, particularmente cuando los fallecimientos de tributarios eran parte de un proceso burocrático que debía seguir el cacique para la respectiva rebaja tributaria.

Gráfico 5: Defunciones según rango etario en los Ayllus de Tarata en 1773.

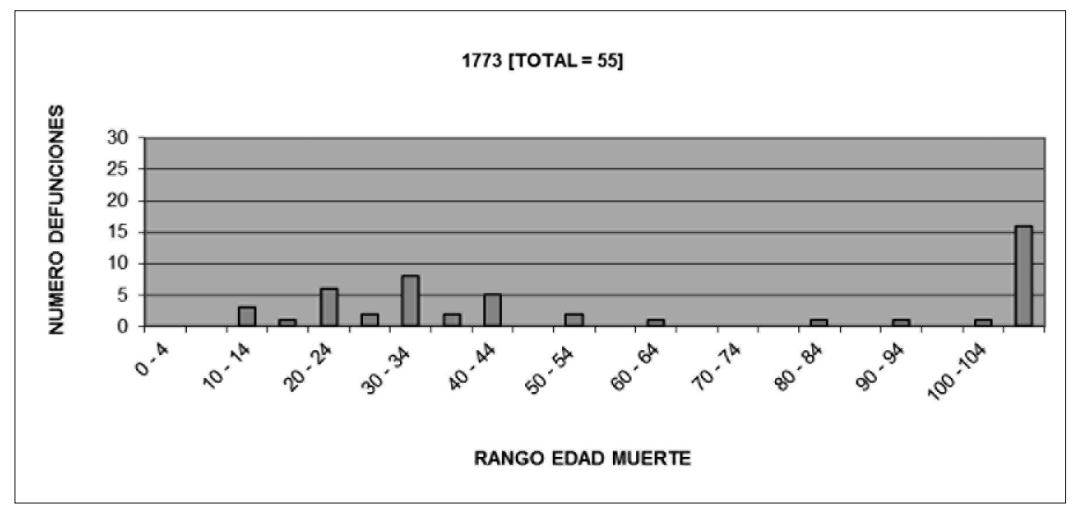

Fuente: Registro efectuado según las cifras proporcionadas por Jorge Hidalgo, Revisita a los Altos de Arica en 1750. Ed. Universidad del Norte, 1978. Gráfico de elaboración propia.

En este registro de fallecimientos correspondiente al año 1773, las cifras nuevamente muestran un alto número de fallecidos sin registro de edad, equivalente en cifras a 16 personas, es decir, un 32,6\%. Los fallecidos con antecedentes etarios son 31. Nuevamente se presenta la situación atípica de ausencia de fallecimientos en etapa temprana, pero se distribuyen antes del umbral de los 55 años, denotando la baja expectativa de vida de esta población. Creemos que estos registros no corresponden a la realidad, ellos tienden a una aproximación pero no son datos reales. Los fallecidos en este periodo se concentran en la etapa etaria de los 20-24 años, por lo que si exceptuamos la muerte causada por alguna epidemia, el fallecimiento a etapa temprana puede corresponder a violencia, accidentes de trabajos o problemas relativos a la salud reproductiva en el caso de las mujeres. Si observamos el gráfico 3 que recoge todos los datos en un periodo de 9 años, los antecedentes resultan muy dispares y hasta artificiosos. En un periodo de 9 años fallecen 367 personas. De ellas, 96 son registradas sin edad. ¿Cómo es posible que en sus casos no se conociera ésta, si en las revisitas se registra prolijamente este antecedente? No tenemos respuestas, pero parece que constituye una 
disonancia en el registro, no menos significativa. Tampoco creemos que correspondan a fallecidos de otras comarcas, producto de la movilidad de población estimada para la época, pero el número es muy significativo y el registro de la revisita atribuye estas cifras a la población originaria de Tarata, sin reparar en otra condición. Como datos adicionales, en el gráfico 4 podemos observar que en 1769, de 85 fallecimientos, 16 se registran sin edad, es decir un 18,8\%. En 1772 se registran fallecimientos, de ellos, 26 constan sin edad, es decir, un $42,5 \%$.

Gráfico 6, 7 y 8: Relación de Masculinidad de la doctrina de Belén en Altos de Arica en los años 1750, 1772 y 1813.

Gráfico 6: Relación de Masculinidad, Doctrina de Belén, 1750

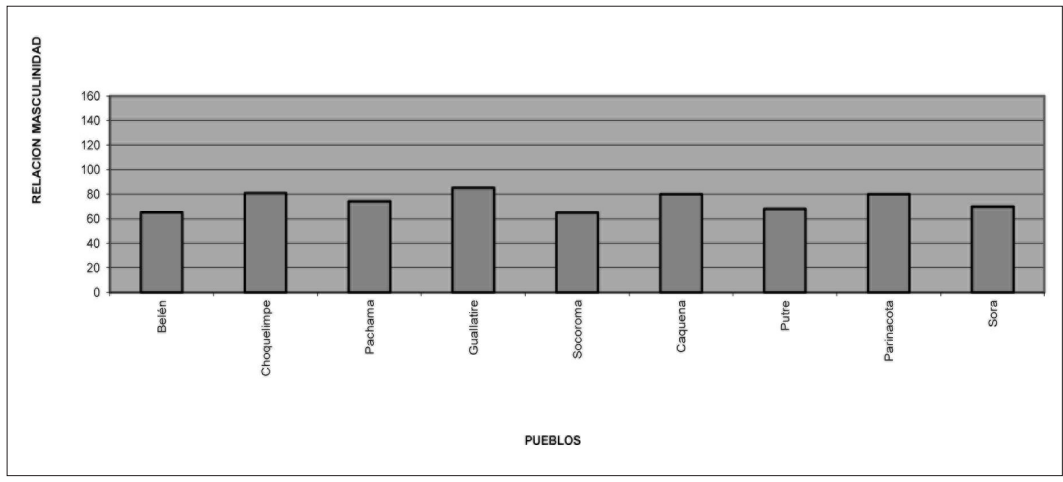

Fuente: Registro efectuado según las cifras proporcionadas por Jorge Hidalgo, Revisita a los Altos de Arica en 1750. Ed. Universidad del Norte, 1978. Gráfico de elaboración propia.

Gráfico 7: Relación de Masculinidad, Doctrina de Belén, 1772.

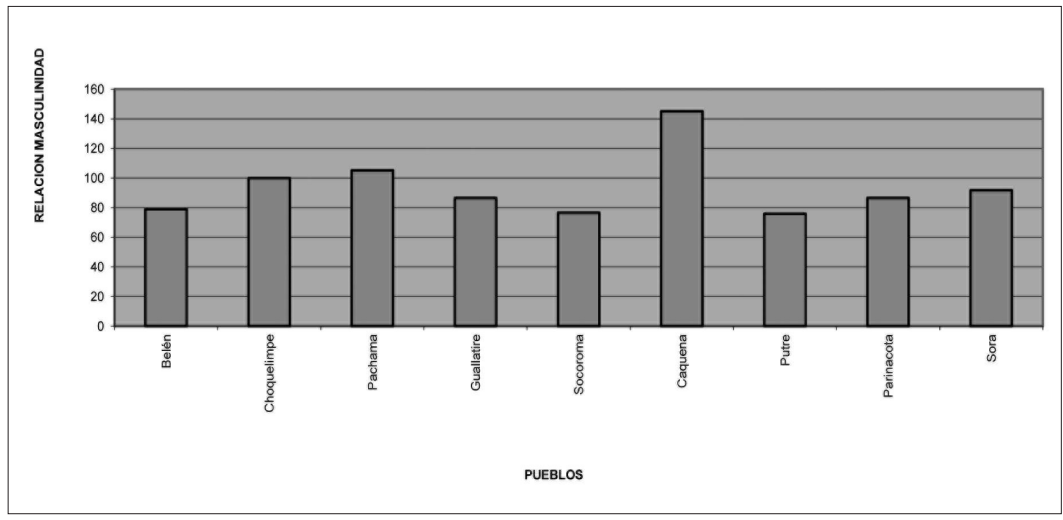

Fuente: Registro efectuado según las cifras proporcionadas por Jorge Hidalgo, Revisita a los Altos de Arica en 1750. Ed. Universidad del Norte, 1978. Gráfico de elaboración propia. 
Gráfico 8: Relación de Masculinidad, Doctrina de Belén, 1813.

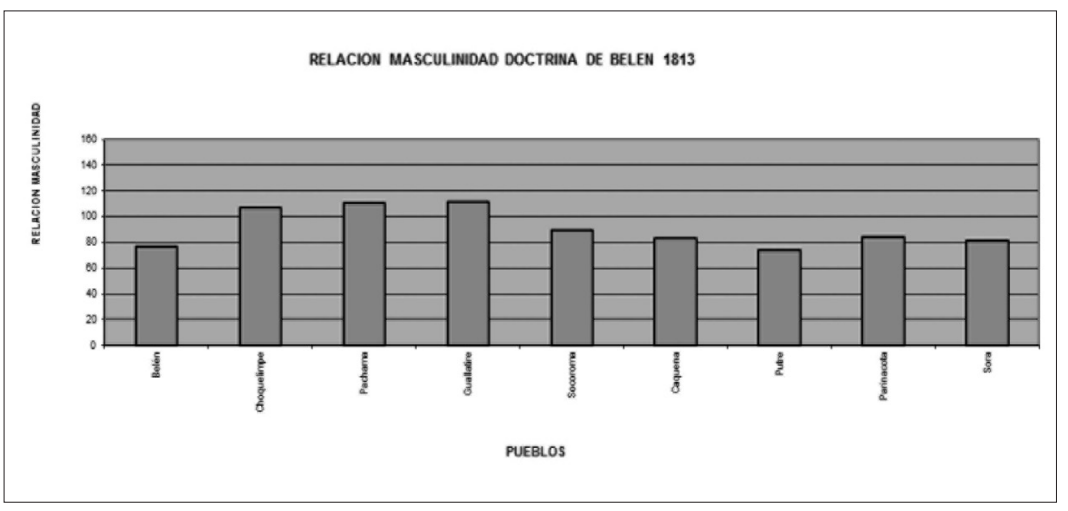

Fuente: Registro efectuado según las cifras proporcionadas por Jorge Hidalgo, Revisita a los Altos de Arica en 1750. Ed. Universidad del Norte, 1978. Gráfico de elaboración propia.

Teniendo en vista estos tres gráficos, podemos realizar una simple apreciación comparativa respecto de las condiciones demográficas de la comunidad allí representada. Los antecedentes expuestos nos muestran una comunidad con un índice de masculinidad negativo. La falta de hombres se extiende hasta el siglo XIX, de modo que en más de siglo y medio no se verifica una recuperación demográfica. ¿Cómo es posible cuando en la región se extendieron las exenciones de mita y en repartimientos como los de Tarata, la población aumenta considerablemente? En el caso de Tarata, la revisita de Egan registra un aumento significativo en el número de tributarios cercano a un $25 \%$ en 17 años, cuestión que denota tanto la movilidad de la población por razones de evasiones tributarias más que por el crecimiento vegetativo. Nos referimos al aumento del número de forasteros, a la transformación de los criterios censales por otros puramente pragmáticos, al incluir en la categoría de tributarios a personas que no poseían esa categoría anteriormente (mestizos sambaigos, cholos y mestizos indígenas). Siguiendo con el análisis comparativo y de modo particular, observando el ayllo de Caquena, observamos una fluctuación muy irregular del índice. Es posible que sucedieran transformaciones de estas características en una población, aunque sus consecuencias se dejarían sentir sobre toda la población. Sin embargo, no hay razones para que este índice bajara significativamente entrado el siglo XIX, luego de la sensible recuperación de 1772.

\section{Conclusiones}

Creemos que los documentos coloniales de las visitas o revisitas indígenas no son, en ningún caso, documentos infalibles. No representan con claridad a la sociedad indígena, recrean una realidad aparente que frente a un análisis 
de las cifras puede ser cuestionado, ya que presenta problemas de coherencia fundamental en sus informaciones. Muchas veces los datos niegan la condición biológica y étnica de la población, demostrando su condición de representación ficticia de la realidad. Sostenemos que estas construcciones argumentales tenían intención y objetivos puntuales enmarcados en el proyecto cultural y fiscal del orden colonial hispano.

Estos textos coloniales delimitan un discurso dominante que se reproduce y replica constantemente. Esta regularidad discursiva debió haberse distanciado de las condiciones materiales de existencia de los indios revisitados, invisibilizando su propia historicidad. Hasta las cifras son objeto de modelación ante los requerimientos cada vez más altos de la fiscalidad imperial. Creemos que un análisis exhaustivo de estos datos nos llevaría a afirmar la idea de que el análisis heurístico convencional no permite confirmar la "validez" de sus antecedentes (Martínez B., 2003). Las voces que son posibles de rescatar no son aquellas relativas a las prácticas discursivas de las sociedades indígenas, sino que son las que tienen relación a sus condiciones vitales silenciadas por la discursividad colonial (Gómez, 2008; Gómez et al., 2010).

Los relatos hispano-coloniales y los documentos administrativos que fueron puestos en tela de juicio para la comprensión de la sociedad indígena prehispánica (Gruzinski, 1995: 11), hoy deben ser estudiados respecto de sus contextos de producción, reglas de enunciación y objetivos de los programas discursivos (Foucault, 1981; Adorno, 1989, 1995; Mignolo, 1982; Todorov, 1982; Pastor, 1982, entre otros), con el fin de clarificar los criterios con los cuales le asignamos veracidad a sus contenidos. Los documentos administrativos coloniales son los que se muestran más susceptibles a este análisis, a pesar de su aparente condición "no literaria". Sin embargo, los problemas que representa su cotejo no difieren significativamente de los de las crónicas de valor histórico. Creemos que estos documentos también son fuentes de "realidades históricas", de voces silenciadas por el discurso colonial, pero requieren de un esfuerzo adicional de análisis y de síntesis de información de valor sociodemográfico para llegar a conclusiones contundentes. Con todo, presentamos este análisis preliminar que no tiene otro fin que mostrar la naturaleza y calibre de las disonancias que puede esconder este tipo de documentación colonial y que, a la vez, nos proporcionan una oportunidad para vislumbrar los procesos de etnificación de tales fuentes (Bixio, 2005: 20), posibilitando el análisis de los discursos de poder, en su amplio sentido, que intentaron la subalternización del otro indígena. La revisita, como cualquier otro documento histórico, debe ser analizada como un texto complejo, que permite la enunciación de diversas voces e intencionalidades, más allá de su tradicional estatuto como fuentes que remiten al pasado indígena. 


\section{Referencias bibliográficas}

\section{Fuentes Secundarias}

\section{a) Artículo}

Abercrombie, T. (1991). "Articulación doble y etnogénesis" en Salomon. F, y Moreno. S. (Coord.) Reproducción y transformación de las sociedades andinas. Quito: Ed. Abda Yala. 197-210.

Araníbar, C. (1963). "Algunos problemas heurísticos en las crónicas de los siglos XVI - XVII". Nueva Corónica 1: 104-135.

Barthes, R. (1970). "El efecto de realidad" en Comunicaciones: Lo verosímil, E. Verón (ed.): 95-101.

Bixio, B. (2005). "Figuras étnicas coloniales; Córdoba del Tucumán. Siglos XVI y XVII" (En línea) Indiana 22. Disponible en: [http://www.iai.spkberlin. de/fileadmin/ dokumentenbibliothek/Indiana/Indiana_22/02_Bixio_neu.pdf] [Consulta: 21 de enero 2011]

Bouysse-Cassagne, T. y HARRIS, O. (1987). "Pacha: en torno al pensamiento Aymara" en Tres reflexiones sobre el pensamiento andino, La Paz: Hisbol.

Brading, D. (1990). "La España de los Borbones y su imperio americano" (coord.) Leslie Bethell, Historia de América Latina, Tomo II. Barcelona: Editorial Crítica. 85-126.

Céspedes Del Castillo, G. (1946). "La Visita como institución Indiana" en Anuario de Estudios Americanos 3: 984-1025.

Díaz, A. y Morong, G. (2006). "El desierto y la miseria: indios y tributación en el sur peruano, Sibaya 1822" en Anthropologica Vol. 24, no.24: 129-152.

Guevara Gil, A., y Salomon, F. (1994). "A 'Personal Visit': Colonial Political Ritual and the Making of Indians in the Andes" en Colonial Latin American Review 3:1-2; 3-35.

Gómez, A. (2008). "Retazos de historia andina. Las instrucciones de las Visitas indígenas como expresión del control fiscal colonial" en Revista Tradición y Saber. Universidad Bernardo O’Higgins. Año V, N 5. Págs. 43-63.

Guevara Gil, A. y Salomon, F. (1996). "La visita personal de indios: ritual político y creación del "indio" en los Andes coloniales". Cuadernos de investigación Nㅜ 1.

Gómez, A. y Ocaranza, F. (2009). "La sociedad andina en el contexto de la economía industrial salitrera: 1880-1920" en Revista Tradición y Saber. Universidad Bernardo O’Higgins. Año VI, № 6. Págs. 173-198. 
Gómez, A., OcaranzA, F. y Osses, G. (2010). "Pesquisando "voces" indígenas en documentos coloniales tardíos: la atribución de sentido como expresión del control fiscal y de la modelación de la sociedad andina colonial (Siglo XVIII)" en Revista Tradición y Saber. Universidad Bernardo O’Higgins. Año VII, Nº 7. Págs. 173-202.

Gómez, A. (2012). "Sociodemografía andina en el área sur Peruana (Siglo XVIII): ayllos de Tarata en el contexto pre-insurreccional de Túpac Amaru" en Revista Digital Nueva Corónica, №2. Revista Académica de la Escuela de Historia de la Universidad Nacional Mayor de San Marcos de Lima. Perú, pp. 137-159.

Gómez, A., Prado, C. y Ocaranza, F. (2014). "Construcción del espacio urbano y modelación social desde la "ciudad letrada": Santiago, Chile (Siglos XVI-XVIII)" en Revista Historelo. Revista de Historia Regional y Local. Universidad Nacional de Colombia. Vol. 6, № 12, julio-noviembre. Pp. 237-270.

Gómez, A., Prado, C. y Ocaranza, F. (2014). "Asientos indígenas en la precordillera de Santiago (Siglos XVI y XVII): estudio de caso" en Revista de Historia y Geografía, № 30. Universidad Católica Cardenal Silva Henríquez. Pp. 57-80.

Hidalgo, Jorge. (1987). "Cacicazgos del sur occidental andino: origen y evolución colonial" en Chiefdons in the Americas. Edited by Robert D. Drennan and Carlo A. Uribe. Lanham: University Press of America.

Hidalgo, J. (1992). "Patrón y revisita de Atacama del Corregidor Alonso de Espejo, ordenada por el virrey Duque de La Palata". Estudios Atacameños 10: 75 - 124.

Hidalgo, J. (1997). "Los yungas de Tarata en el siglo XVIII", Rafael Barón (Editor) 425-442. Antropología, Arqueología e Historia de los Andes. Libro Homenaje a María Rostworoswski. Lima: Instituto de Estudios Peruanos.

Hidalgo, J., Arévalo, P., Marsilli, M. y Calogero, S. (1988). "Patrón de la Doctrina de Belén en 1813: un caso de complementariedad tardía" en Documento de Trabajo No 4. Arica: Universidad de Tarapacá.

Hidalgo, J., Gómez, A., Castro, N. y Prado, C. (1996). "La Revisita de Tarata de 1773 - 1774 del Corregidor de Arica Demetrio Egan". (Documento inédito).

Hidalgo, J., Castro, N. y González, S. (2004). "La revisita de Codpa (Altos de Arica) de 1772-73 efectuada por el corregidor Demetrio Egan" en Chungará, 36(1): 103-204.

Martínez, J. L. (1992). "Textos y palabras. Cuatro documentos del Siglo XVI" en Estudios Atacameños 10: 133-147.

Martínez, J. L. (1995). "Pública voz y fama: una aproximación a los espacios discursivos coloniales". Revista Chilena de Humanidades 16: 27-40.

Martínez, J. L. (2000ª). "Voces, discursos e identidades coloniales en los Andes del siglo XVI". Martínez, J. L. (editor). 127-158. Los discursos sobre los otros. Una aproximación metodológica interdisciplinaria. Santiago: Ediciones Facultad de Filosofía y Humanidades, LOM. 
Martínez, J. L. (2000b). "Documentos y discursos. Una reflexión desde la etnohistoria". Martínez, J. L. (editor) 9-24. Los discursos sobre los otros. Una aproximación metodológica interdisciplinaria. Santiago: Ediciones Facultad de Filosofia y Humanidades, LOM.

Mignolo, W. (1992). "La cuestión de la letra en la legitimación de la conquista" en Kohut, Karl (coord.) De conquistadores y conquistados. Realidad, Justificación, representación. Frankfurt. 97-112.

Mignolo, W. (1981). "El metatexto historiográfico y la historiografía indiana" Modern Languages Notes, Vol. 96: 358-402.

Morong, G. (2001). "Textualidad hispana y dominación colonial; la construcción de la legitimidad hispana por el dominio del Tawantinsuyu durante la administración toledana 1567-1572" en Anuario de Post-Grado 4: 267-300.

Morong, G. (2011). "Identidades étnicas coloniales en el Reino de Chile, S. XVIXVII", Tradición y Saber 8: 169-183.

Murra, J. (1964). "Una apreciación etnológica de la visita" en Visita hecha a la provincia de Chuicuito por Garci Diez de San Miguel en el año 1567. Lima: Ediciones e la Casa de la Cultura. pp. 419 - 442.

Murra, J. (1968). Un reino aymará en 1567. Texto traducido y mimeografiado por Oscas Espoueys (1970). s/r. Corresponde a la publicación del artículo en Ethnohistory, tomo XV, № 2: 115-151.

Pease, F. (1978). "Las visitas como testimonio andino" en Quesada, M., Pease. F. y Sobrevilla D. (eds.) Historia, problema y promesa. Homenaje a Jorge Basadre. Lima: Universidad Católica del Perú.

Spalding, K. (1970). "Tratos mercantiles del Corregidor de Indios y la formación de la hacienda serrana en el Perú" en América Indígena 3, Vol. XXX.

Tord, J. E. (1974). "El corregidor de indios del Perú: comercio y tributos" en Historia y Cultura 8: 187-198.

Van Dijk, T. A. (1999). "El análisis crítico del discurso" en Anthropos 186: 23-36.

Wachtel, N. (1978). "Hommes d'éau: le problème uru (XVI -XVII siècle)". Annales 33, 5 - 6: 1127-1159.

Zagalsky, P. (2009). "Huellas en las revisitas: imposiciones coloniales y tensión social", Memoria Americana 17-2: 11-40.

\section{b) Libros}

Aguirre Beltrán, G. (1957). El proceso de aculturación. México: Universidad Nacional Autónoma de México. 
Aróstegui, J. (1995). La investigación histórica: teoría y método, Barcelona: Editorial Crítica.

Bajtín, M. (1982). La estética de la creación verbal. México: Siglo XXI.

Cook, D. (1975). Tasa de la visita general de Francisco de Toledo. Lima: Universidad Nacional Mayor de San Marcos.

Foucault, M. (1972). La Arqueología del Saber, México: Siglo XXI.

Foucault, M. (1980). El orden del Discurso, Barcelona: Tusquets.

Golte, J. (1980). Repartos y rebeliones: Tupac Amaru y las contradicciones de la economía colonial. Lima: Instituto de Estudios Peruanos.

Gruzinski, S. (1995). La colonización de lo imaginario. Sociedades y occidentalización en el México español. Siglos XVI-XVIII. México: FCE.

Gruzinski, S. (2010). Las cuatro partes del mundo. Historia de una mundialización. México: FCE.

Levillier, R. (1940). Don Francisco de Toledo. Supremo Organizador del Perú. Su vida, su obra (1515-1582). Tomo II. Buenos Aires: Colección de publicaciones históricas de la Biblioteca del Congreso Argentino.

López-Baralt, M. (1993). Guaman Poma; autory artísta. Lima: Fondo Editorial PUCP. O'Phelan, S. (1988). Un siglo de rebeliones anticoloniales". Perú y Bolivia, 17001783. Cusco: Centro de Estudios Regionales Andinos Bartolomé de las Casas.

O'Phelan, S. (1995). La gran rebelión de los Andes. De Túpac Amaru a Túpac Catari. Cusco: Centro de Estudios Regionales Andinos Bartolomé de las Casas.

O'Phelan, S. (1997). Kuracas sin sucesiones. Del cacique al alcalde de indios: Perú y Bolivia, 1750-1835. Cusco: Centro de Estudios Regionales Andinos Bartolomé de Las Casas.

Ong, W. (1987). Oralidad y Escritura. Tecnologías de la Palabra. México: FCE.

Ots Capdequí, J. M. (1969). Historia del derecho español en América y del derecho indiano. Madrid: B. J. Aguilar.

Pastor, B. (1983). Discurso narrativo de la Conquista de América. La Habana: Casa de Las Américas.

Pease, F. (1995). Las crónicas y los Andes. Lima: Universidad. Católica del Perú, FCE.

Szeminski, J. (1984). De la utopía Tupamarista. Lima: Fondo editorial PUCP.

Tandeter, E. (1992). Coacción y mercado. La minería de la plata en el Potosí CoIonial, 1692-1826. Archivos de Historia Andina № 15. Cusco: Centro de Estudios Regionales Andinos Bartolomé de Las Casas. 
Spalding, K. (1974). De Indio a Campesino: Cambios en la estructura social del Perú Colonial. Lima: Instituto de Estudios Peruanos.

Tord, J. y Laso, C. (1981). Hacienda, Comercio, Fiscalidad y Luchas Sociales (Perú Colonial). Lima: Biblioteca Peruana de Historia, Economía y Sociedad.

White, H. (1992). El contenido de la forma. Narrativa, discurso y representación histórica. Madrid: Paidós. 